CLINICAL STUDY

\title{
Autosomal dominant neurohypophyseal diabetes insipidus in a Swiss family, caused by a novel mutation (C59D/A60W) in the neurophysin moiety of prepro-vasopressin-neurophysin II (AVP-NP II)
}

\author{
Christa E Flück, Johnny Deladoëy, Sujatha Nayak ${ }^{2}$, Oliver Zeller ${ }^{1}$, Peter Kopp ${ }^{2}$ and Primus E Mullis \\ Department of Paediatric Endocrinology, Diabetology and Metabolism, University Children's Hospital, ${ }^{1}$ Department of Neuroradiology, \\ University Hospital Inselspital, 3010 Bern, Switzerland and ${ }^{2}$ Division of Endocrinology, Metabolism \& Molecular Medicine, Northwestern University, \\ Chicago, IL 60611, USA \\ (Correspondence should be addressed to Primus E Mullis, Department of Paediatric Endocrinology, Diabetology and Metabolism, University Children's \\ Hospital, Inselspital, CH-3010 Bern, Switzerland; Email: primus.mullis@insel.ch)
}

\begin{abstract}
Objective: To study clinical, morphological and molecular characteristics in a Swiss family with autosomal dominant familial neurohypophyseal diabetes insipidus (adFNDI).

Participants and methods: A 15-month-old girl presenting with symptoms of polydipsia and polyuria was investigated by water deprivation test. Evaluation of the family revealed three further family members with symptomatic vasopressin-deficient diabetes insipidus. T1-weighted magnetic resonance images of the posterior pituitary were taken in two affected adult family members and molecular genetic analysis was performed in all affected individuals.

Results: The water deprivation test in the 15-month-old child confirmed the diagnosis of vasopressindeficient diabetes insipidus and the pedigree was consistent with autosomal dominant inheritance. The characteristic bright spot of the normal vasopressin-containing neurophypophysis was absent in both adults with adFNDI. Direct sequence analysis revealed a new deletion (177-179 $\Delta$ CGC) in exon 2 of the AVP-NP II gene in all affected individuals. At the amino acid level, this deletion eliminates cysteine $59(\mathrm{C} 59 \Delta)$ and substitutes alanine 60 by tryptophan (A60W) in the AVP-NP II precursor; interestingly, the remainder of the reading frame remains unchanged. According to the threedimensional structure of neurophysin, C59 is involved in a disulphide bond with C65.

Conclusions: Deletion of C59 and substitution of A60W in the AVP-NP II precursor is predicted to disrupt one of the seven disulphide bridges required for correct folding of the neurophysin moiety and thus disturb the function of neurophysin as the vasopressin transport protein. These data are in line with the clinical and morphological findings in the reported family with adFNDI.
\end{abstract}

European Journal of Endocrinology 145 439-444

\section{Introduction}

Autosomal dominant familial neurohypophyseal diabetes insipidus (adFNDI) is a form of diabetes insipidus caused by absence of circulating arginine vasopressin (AVP), a nonapeptide derived from a larger single chain vasopressin-neurophysin (AVP-NP II) precursor synthesised by magnocellular neurones of the hypothalamus. Various heterozygous mutations in the coding sequence of the AVP-NP II gene have been identified in patients with adFNDI (1). The AVP-NP II gene is located on chromosome 20p13 and consists of three exons.

Clinically, the deficiency in secretion of the antidiuretic hormone arginine vasopressin (AVP) becomes apparent several months to years after birth and progresses in severity from partial to nearly complete. The postnatal progression has been explained by degeneration of the AVP producing magnocellular neurohypophyseal neurones, as a result of intracellular retention and a cytotoxic effect of the mutated precursor. Several lines of evidence support this concept. Autopsy studies of patients with adFNDI revealed degeneration of magnocellular vasopressinergic neurones in the supraoptic and paraventricular hypothalamic nuclei $(2-5)$. The progressive deficiency in AVP is typically accompanied by the disappearance of the posterior pituitary bright spot signal on T1weighted magnetic resonance imaging (MRI) (1, 6-9).

We report the results of clinical, morphological and molecular studies of a Swiss family with adFNDI in three generations. Further, co-segregation of clinical 
symptoms and the $\mathrm{C} 59 \Delta / \mathrm{A} 60 \mathrm{~W}$ mutation in the AVPNP II precursor with the absence of the characteristic T1-hyperintense appearance of the neurohypophysis is demonstrated.

\section{Participants and methods}

\section{Participants}

We studied four members of a pedigree of three generations (Fig. 1). The index patient (III-5), a Swiss female child presented at the age of 15 months with polydipsia (fluid intake of 3-4 litres per day) and polyuria, but on physical examination she was otherwise healthy. She was investigated first by water deprivation test (10).

The family history revealed central diabetes insipidus in three other family members, namely her mother (II-3), one of her uncles (II-2) and her maternal grandfather (I-1) who might be the source of the initial germ-line mutation. Two of these family members (I-1, II-2) had been evaluated some years previously by water deprivation tests (10): member I-1 had developed symptoms at school age and member II-2 at the age of 2-3 years. In member II-3, the diagnosis was established solely on clinical grounds at the age of 18 months because formal testing was refused. All affected family members have now been receiving treatment with 1-desamino-8-D-arginine vasopressin (DDAVP) for several years, except the index patient (III-5), in whom DDAVP substitution therapy was started only recently, after formal testing. Individuals I-1 and II-2, then 58 and 32 years of age, gave informed consent to undergo T1-weighted MRI of their posterior pituitary glands. However, in the index patient, MRI was unfortunately refused by the parents. Molecular genetic analysis were performed in the index patient (III-5), her parents (II-3 and II-4) and family members I-1 and II-2.

\section{Diagnostic tests}

A water deprivation test was performed in the index patient according to standard procedures (10) using DDAVP to terminate the 7 -h fluid restriction period used for differentiating central from nephrogenic diabetes insipidus (11).

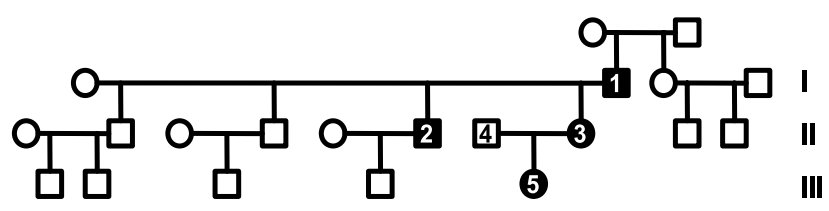

Figure 1 Pedigree of the family with adFNDI. Affected individuals are indicated in black.

\section{MRI studies}

Two affected family members (I-1 and II-2) were studied on a 1,5 T High Resolution MRI-Scanner (Siemens Vision, Erlangen, Germany) using sagittal, coronal and T1-weighted spin-echo sequences (response time $350 \mathrm{~ms}$, echo time $12 \mathrm{~ms}$, slice thickness $3.0 \mathrm{~mm}$, field of view $180 \times 180 \mathrm{~mm}$, Matrix 230*256). Series were acquired without intravenous application of contrast media and without fat suppression.

\section{Molecular genetic analysis}

After we had obtained informed consent from the participants, genomic DNA was extracted from peripheral leucocytes (12). All three exons of the AVP-NP II gene were amplified using intronic primers (exon 1 sense: TCGCCTCCACGGGAACACCTGCGGACATAA; exon 1 antisense: AGCACTGCCCGCTATGGCTGCCCTGAGATG; exon 2/3 sense: TCGCTGCGTTCCCCTCCAACCCCTCGACTC; exon 2/3 antisense: CCTCTCTCCCCTTCCCTCTTCCCGCCAGAG) with conditions reported previously (13). The PCR products were purified with Centricon 100 columns (Amicon, Beverly, MA, USA), and both strands were sequenced directly using a dRhodamine terminator cycle sequencing kit (Applied Biosystems, Foster City, CA, USA). Sequencing products were analysed on a 377 DNA sequencer (Applied Biosystems). All the data were confirmed by a second sequence analysis from both sides.

\section{Results}

\section{Clinical diagnosis}

During water deprivation testing the 15-month-old index patient developed moderate dehydration (299 mosmol/kg) without urinary concentration (87 mosmol/kg). AVP was unmeasurably low. Administration of DDAVP stopped urinary flow completely, consistent with the diagnosis of central AVP-deficient diabetes insipidus.

\section{MRI studies}

The characteristic high-intensity signal of the posterior part of the pituitary gland in unenhanced T1-weighted spin-echo sequences without fat suppression was completely absent in both patients studied (Fig. 1: I-1, II-2). Two representative sagittal images are shown in Fig. 2 in comparison with the image of a control individual showing the bright spot of a normal neurohypophysis.

\section{Molecular genetic analysis}

Analysis of the pedigree is consistent with an autosomal dominant transmission of diabetes insipidus 

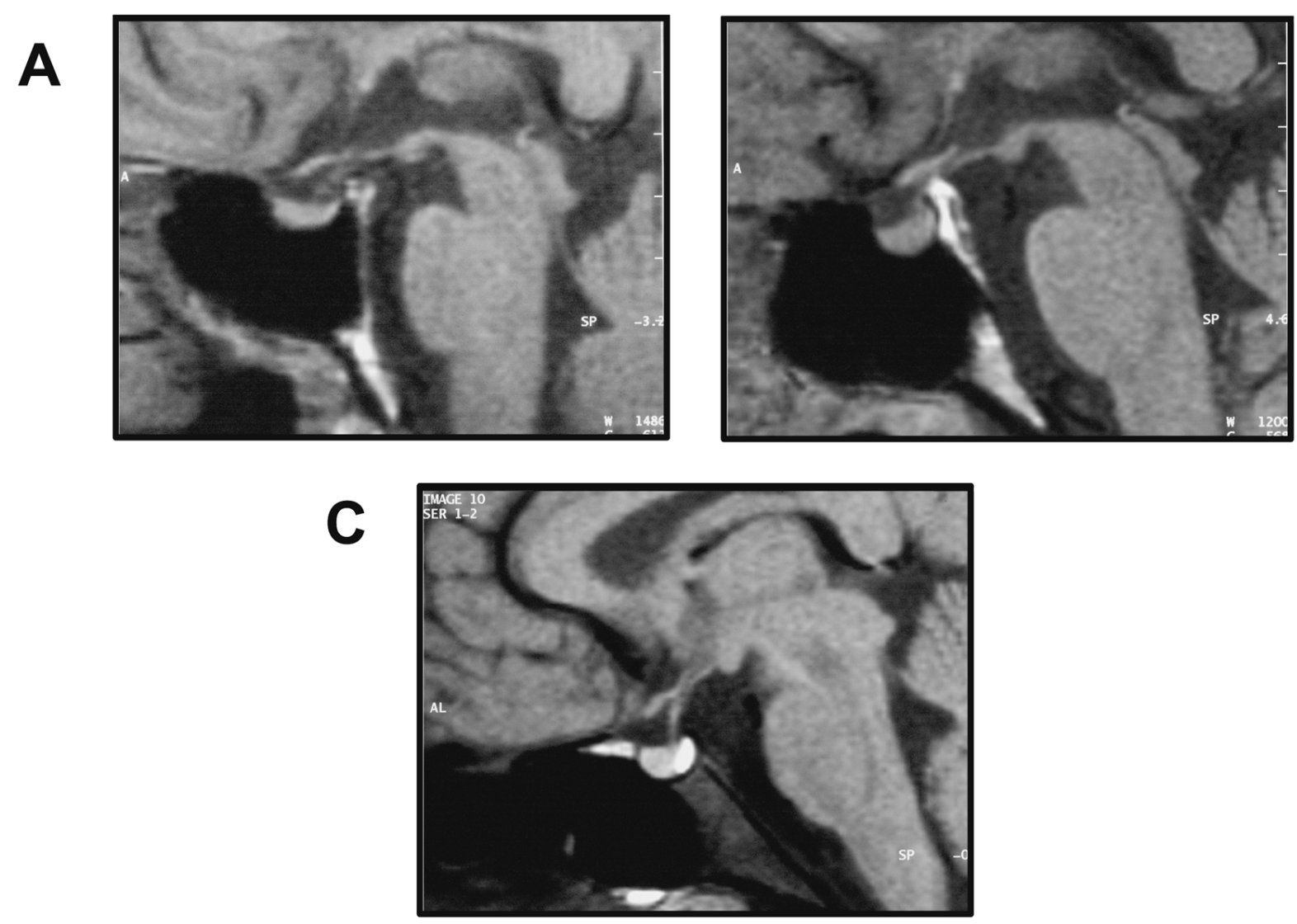

Figure $2 \mathrm{MRI}$ of two affected family members in comparison with a normal control. Representative T1-weighted images of adFNDI patients I-1 (A) and II-2 (B) are shown. Note the normal high intensity signal of the posterior lobe of the pituitary gland in an unaffected control individual $(\mathrm{C})$, in contrast to the absence of this bright spot in the affected individuals.

(Fig. 1). Sequence analysis of the AVP-NP II coding sequence in all the affected individuals revealed a deletion 177-179 $\triangle \mathrm{CGC}$ in exon 2 (Fig. 3; nomenclature according to 14,15$)$. At the amino acid level, this deletion eliminates cysteine 59 and it substitutes alanine 60 by tryptophan (A60W). Although this deletion affects the second and third base of codon 59, in addition to the first base of codon 60 , the remainder of the reading frame remains unaffected (Fig. 4). According to the three-dimensional structure of neurophysin, C59 is involved in a disulphide bond with C65 (1). According to the traditionally used nomenclature with separate numbering for the signal peptide, AVP, neurophysin and copeptin, this alteration corresponds to $\mathrm{C} 28$ and A29W (Fig. 4) $(1,15)$.

\section{Discussion}

Autosomal dominant familial neurohypophyseal diabetes insipidus is caused by mutations in the AVP-NP II gene $(1,13)$. The AVP-NP II gene is located on chromosome 20p13 and has three exons, with an open reading frame of $492 \mathrm{bp}$. Exon 1 encodes a signal peptide, AVP, and the N-terminal portion of NP II; exon 2 encodes the central region of NP II; exon 3 encodes the C-terminal part of NP II and copeptin, a glycoprotein with unknown function (16). About 30 distinct mutations have been reported in the AVP-NP II gene causing adFNDI $(13,15,17-34)$. The mutations include small deletions and missense and nonsense mutations that affect the signal peptide, the AVP moiety, or the AVP carrier protein, NP II (1). All these dominant mutations described so far contrast with the recently reported recessive mutation in AVP (35). In this autosomal recessive case, the three affected children, offspring of first-degree relatives, were homozygous for a transition C77T in exon 1, replacing P26L (P7L within AVP) (Fig. 4). The mutated form of AVP was a weak agonist with approximately 30-fold reduced binding to the human AVPR2 receptor. In contrast to patients with adFNDI, who present with a progressive decrease in AVP concentrations, the mutated AVP was increased in all three children and there was a further, 30-fold increase during water deprivation (35).

The mutation in the pedigree presented here eliminates a cysteine (C59D) believed to be involved 
T GCGCG GACG A GCT G GGC T GC Cys Ala Asp Glu Leu Gly $\frac{\text { Cys }}{\text { Gla }}$

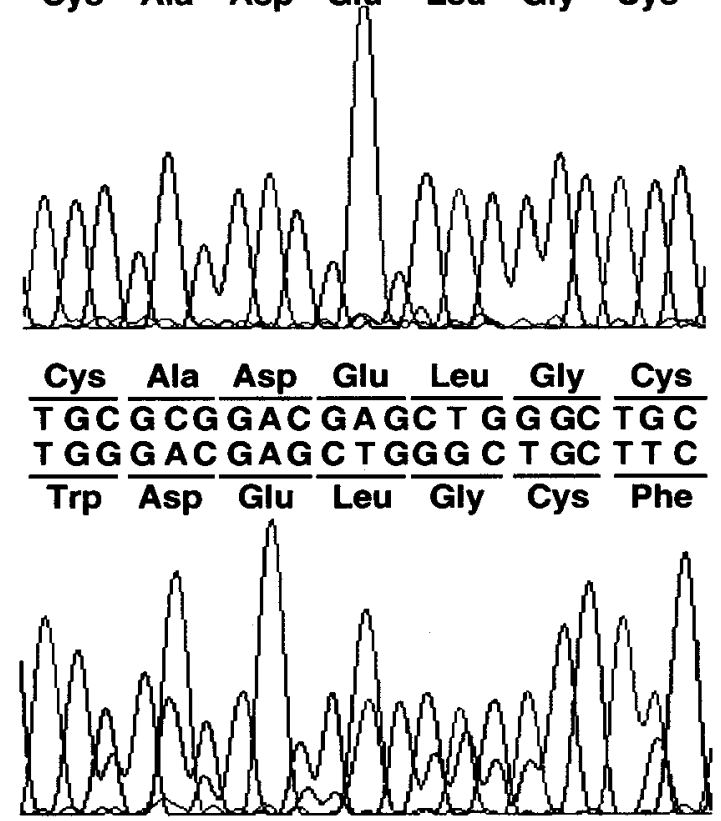

Figure 3 Sequence analysis. Upper panel: chromatogram of the unaffected male II-4 showing the wild type sequence. Lower panel: chromatogram of family member II-3 with a heterozygous deletion $177-179 \Delta$ CGC in one allele. This leads to a deletion of C59 and a frameshift, resulting in substitution of A60W in the NP II moiety. Subsequently, the reading frame corresponds to the wild type.

in the formation of a disulphide bond with cysteine 65 as predicted by sequential proteolysis and the crystal structure of bovine NP II $(18,36,37)$. Interestingly, at the same locus a transition $\mathrm{T} 175 \mathrm{C}$ resulting in substitution of $\mathrm{C} 59 \mathrm{R}$ has been previously reported in a family with adFNDI (1). However, the mutation in our study family is quite different and unusual because the deletion C $59 \Delta$ is followed by a frameshift that affects only the following codon (A60W), but not the remainder of the reading frame, which is entirely preserved (Fig. 3). The structural consequence of this mutation (C59A, $\mathrm{A} 60 \mathrm{~W})$ in the neurophysin moiety is expected to alter correct folding of the AVP-NP II precursor by eliminating a disulphide bridge (C59-C65) (1, 18, 36 , 37). It is noteworthy that the only known frameshift mutation in the AVP-NP II gene identified to date occurred in the Brattleboro rat and is associated with a recessive mechanism of disease (38).

Incorrect folding by elimination or introduction of cysteine residues is a commonly observed mechanism underlying abnormal folding of AVP-NP II in adFNDI $(1,15)$. Recently, a report of the expression of mutated AVP-NP II in different transfected cells documented retention of the mutated precursor molecule in the endoplasmic reticulum $(17,39-41)$. Furthermore, there is evidence for the toxicity of mutant precursors or their degradation products in cultured neuro2 $\mathrm{A}$ neuroblastoma cells (40). Other mutations in the NP II moiety are believed to affect flexibility or rigidity of the molecule, or they may alter the structure of the binding pocket and thus impair binding of AVP to its carrier protein (1). Mutations in the signal peptide impair or misdirect cleavage of the signal peptide from the N-terminus of AVP $(1,41,42)$. In addition to the cytotoxicity caused by the misfolded mutant AVP-NPII precursors, heterodimer formation between the wildtype and mutant precursors may contribute to the pathogenesis of adFNDI through a dominant negative mechanism (43).

Overall, the fact that all the mutations affecting the signal peptide or the neurophysin moiety result in amino acid substitutions or deletions of residues that are important for processing, folding or oligomerization of the precursor suggests a possible unifying molecular mechanism for the development of the disease $(1,18)$.

In patients with adFNDI who were started on treatment early and have been receiving DDAVP substitution therapy for many years, secretion of endogenously misfolded AVP-NP II might be blocked by the exogenous DDAVP application and, therefore, the suggested cytotoxic effect of this altered peptide could be reversible for a certain period of time, as has been seen in some autosomal dominant forms of $\mathrm{GH}$ deficiency $(44,45)$. The observation that the highintensity signal of the neurohypophysis was undetectable in both patients I-1 and II-2, who have been receiving treatment with DDAVP for more than 30 years, argues against the possibility of a reversible process in adFNDI.

The observed absence of the so-called bright spot of the posterior pituitary gland in patients with adFNDI is believed to be caused by the absence of AVP-containing neurovesicles in axonal endings, thus reflecting loss of posterior lobe function $(6-9,26)$.

The findings of our study demonstrate the co-

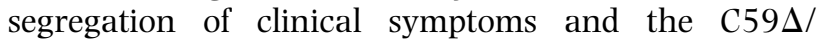
A60W mutation in the AVP-NP II precursor, with absence of the characteristic T1-hyperintense appearance of the neurohypophysis in both of the two adult adFNDI patients studied. These findings are in line with the suggested pathomechanism for adFNDI $(17,39-$ $41,43)$. The mechanism underlying adFNDI is thus distinct from some forms of autosomal dominant $\mathrm{GH}$ deficiency that has preserved inducible GH secretion and absence of cytotoxic degeneration of somatotrophs $(44,45)$.

In conclusion, the deletion $\mathrm{C} 59 \Delta / \mathrm{A} 60 \mathrm{~W}$ is predicted to result in an AVP-NP II precursor that is misfolded and thus retained within the magnocellular neurones. In addition, MRI results from the affected patients support the molecular mechanism postulated for the majority of AVP-NP II mutations associated with adFNDI $(17,39-41,43)$. 


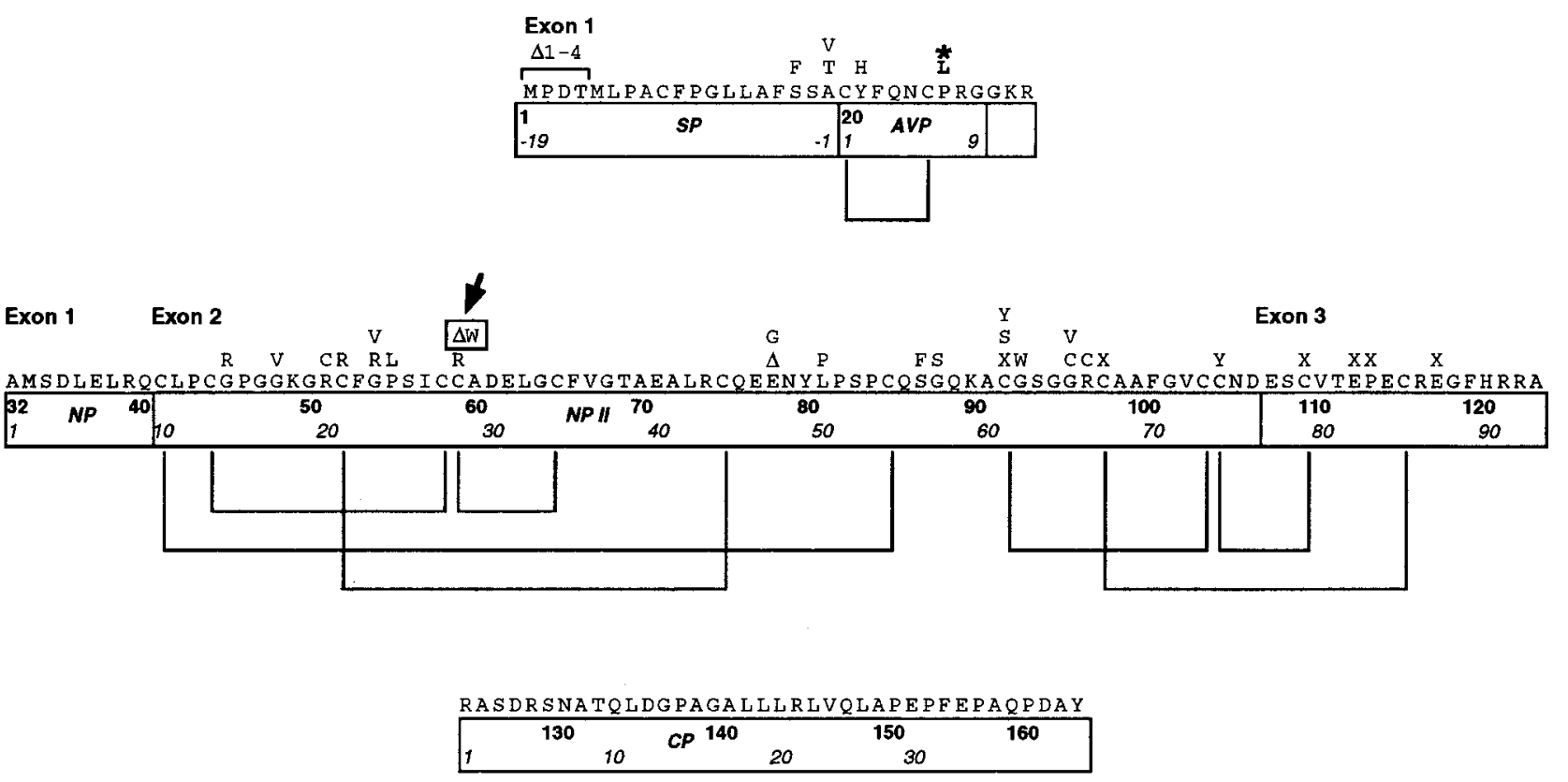

Figure 4 Schematic structure and amino acid sequence of the AVP-NP II protein precursor. Exon 1 encodes the signal peptide (SP), vasopressin $(A V P)$, and the $\mathrm{N}$-terminus of neurophysin (NP). Exon 2 encodes the major part of $N P$ II, and exon 3 encodes the C-terminus of NP II and copeptin (CP). Published mutations associated with adFNDI are shown above the wild-type sequence, the recessive mutation in AVP (P26L) is in bold and indicated by *. $\Delta$, deletion; X, premature stop codon; the arrow denotes the novel mutation identified in this pedigree, $\mathrm{C} 59 \Delta / \mathrm{A} 60 \mathrm{~W}$. Numbering of amino acids starts at the methionine of the signal peptide. The traditional numbering of the different peptides arising from the prepro-AVP-NP II precursor is shown below in italics. Lines indicate the cysteine bridges in AVP and NP II. (Modified from reference 15, with permission).

\section{Acknowledgements}

This work was partly supported by a Northwestern University New Investigator Award from the Howard Hughes Medical Institute to P K, and by a grant from the Swiss National Science Foundation to P E M (3253714.98).

\section{References}

1 Hansen LK, Rittig S \& Robertson GL. Genetic basis of familial neurohypophyseal diabetes insipidus. Trends in Endocrinology and Metabolism $19978363-372$.

2 Forssman H. On hereditary diabetes insipidus with special regard to a sex-linked form. Acta Medica Scandinavica 1945159 (Suppl) $1-196$.

3 Braverman LE, Mancini MP \& McGoldrick DM. Hereditary idiopathic diabetes insipidus: a case report with autopsy findings. Annals of Internal Medicine 196563 503-508.

4 Nagai I, Li CH, Hsieh SM, Kizaki T \& Urano Y. Two cases of hereditary diabetes insipidus, with an autopsy finding in one. Acta Endocrinologica 1984105 318-323.

5 Green JR, Buchan GC, Alvord ECJ \& Swanson AG. Hereditary and idiopathic types of diabetes insipidus. Brain 196790 707-714.

6 Colombo N, Berry I, Kucharczyk J, Kucharczyk W, de Groot J, Larson $\mathrm{T}$ et al. Posterior pituitary gland: appearance on MR images in normal and pathologic states. Radiology 1987165 481-485.

7 Fujisawa I, Nishimura K, Asato R, Togashi K, Itoh K, Noma S et al. Posterior lobe of the pituitary in diabetes insipidus: MR findings. Journal of Computer Assisted Tomography 198711 221-225.
8 Miyamoto S, Sasaki N \& Tanabe Y. Magnetic resonance imaging in familial central diabetes insipidus. Neuroradiology 199133 $272-273$.

9 Kurokawa H, Fujisawa I, Nakano Y, Kimura H, Akagi K, Ikeda K et al. Posterior lobe of the pituitary gland: correlation between signal intensity on T1-weighted MR images and vasopressin concentration. Radiology 1998207 79-83.

10 Czernichow P. Testing water regulation. In Diagnostics of Endocrine Function in Children and Adolescents, edn 2, pp 230240. Ed MB Ranke. Heidelberg/Leipzig: Johannn Ambrosius Barth Verlag, 1996.

11 Hendricks SA, Lippe B, Kaplan SA \& Lee WNP. Differential diagnosis of diabetes insipidus: use of DDAVP to terminate the seven-hour water deprivation test. Journal of Pediatrics 198198 244-246.

12 Mullis P, Patel M, Brickell PM \& Brook CGD. Isolated growth hormone deficiency: analysis of the growth hormone (GH) releasing hormone gene and the $\mathrm{GH}$ gene cluster. Journal of Clinical Endocrinology and Metabolism 199070 187-191.

13 Ito M, Mori Y, Oiso Y \& Saito H. A single base substitution in the coding region for neurophysin II associated with familial central diabetes insipidus. Journal of Clinical Investigation $199187725-$ 728.

14 Antonarakis SE \& the Nomenclature Working Group. Recommendations for a nomenclature system for human gene mutations. Human Mutation 199811 1-3.

15 Rutishauser J, Kopp P, Gaskill MB, Kotlar KJ \& Robertson GL. A novel mutation $(\mathrm{R} 97 \mathrm{C})$ in the neurophysin moiety of preprovasopressin-neurophysin II associated with autosomal dominant neurohypophyseal diabetes insipidus. Molecular Genetics and Metabolism 199967 89-92.

16 Sausville E, Carney D \& Battey J. The human vasopressin gene is linked to the oxytocin gene and is selectively expressed in a 
cultured lung cancer cell line. Journal of Biological Chemistry $198526010236-10241$.

17 Siggaard C, Rittig S, Corydon TJ, Andreasen PH, Jensen TG, Andresen BS et al. Clinical and molecular evidence of abnormal processing and trafficking of the vasopressin preprohormone in a large kindred with familial neurohypophyseal diabetes insipidus due to a signal peptide mutation. Journal of Clinical Endocrinology and Metabolism 199984 2933-2941.

18 Rittig S, Robertson GL, Siggaard C, Kovacs L, Gregersen N, Nyborg $J$ et al. Identification of 13 new mutations in the vasopressin-neurophysin II gene in 17 kindreds with familial autosomal dominant neurohypophyseal diabetes insipidus. American Journal of Human Genetics $1996 \mathbf{5 8}$ 107-117.

19 Bahnsen U, Oosting P, Swaab DF, Nahke P, Richter D \& Schmale H. A missense mutation in the vasopressin-neurophysin precursor gene cosegregates with human autosomal dominant neurohypophyseal diabetes insipidus. EMBO Journal 199211 19-23.

20 McLeod JF, Kovacs L, Gaskill MB, Rittig S, Bradley GS \& Robertson GL. Familial neurohypophyseal diabetes insipidus associated with a signal peptide mutation. Journal of Clinical Endocrinology and Metabolism 199377 599A-599G.

21 Yuasa H, Ito M, Nagasaki H, Oiso Y, Miyamoto S, Sasaki N et al. Glu-47, which forms a salt bridge between neurophysin-II and arginine vasopressin, is deleted in patients with familial central diabetes insipidus. Journal of Clinical Endocrinology and Metabolism 199377 600-604.

22 Krishnamani MRS, Phillips JA \& Copeland KC. Detection of a novel arginine vasopressin defect by dideoxy fingerprinting. Journal of Clinical Endocrinology and Metabolism 1993 77 596-598.

23 Repaske DR \& Browning JE. A de novo mutation in the coding sequence for neurophysin-II (Pro24 $\rightarrow$ Leu) is associated with onset and transmission of autosomal dominant neurohypophyseal diabetes insipidus. Journal of Clinical Endocrinology and Metabolism 199479 421-427.

24 Nagasaki H, Ito M, Yuasa H, Saito H, Fukase M, Hamada K et al. Two novel mutations in the coding region for neurophysin-II associated with familial central diabetes insipidus. Journal of Clinical Endocrinology and Metabolism 199580 1352-1356.

25 Rittig S, Siggaard C \& Ozata M. Familial neurohypophyseal diabetes insipidus due to mutation that substitutes histidine for tyrosine-2 in the antidiuretic hormone. Journal of Investigative Medicine 199644 387A (Abstract).

26 Rutishauser J, Boni-Schnetzler M, Boni J, Wichmann W, Huisman T, Vallotton MB et al. A novel point mutation in the translation initiation codon of the pre-pro-vasopressin-neurophysin II gene: cosegregation with morphological abnormalities and clinical symptoms in autosomal dominant neurohypophyseal diabetes insipidus. Journal of Clinical Endocrinology and Metabolism 199681 192-198.

27 Ueta Y, Taniguchi S, Yoshida A, Murakami I, Mitani Y, Hisatome I et al. A new type of familial central diabetes insipidus caused by a single base substitution in the neurophysin II coding region of the vasopressin gene. Journal of Clinical Endocrinology and Metabolism 199681 1787-1790.

28 Gagliardi PC, Bernasconi S \& Repaske DR. Autosomal dominant neurohypophyseal diabetes insipidus associated with a missense mutation encoding Gly23 $\rightarrow$ Val in neurophysin II. Journal of Clinical Endocrinology and Metabolism 199782 3643-3646.

29 Gonking NQ, Chertow BS, Robertson GL, Rittig S, Siggaard C \& Pedersen EB. Familial neurohypophyseal diabetes insipidus. A novel mutation presenting with enuresis. Journal of Investigative Medicine 199745 29A (Abstract).

30 Heppner C, Kotzka J, Bullmann C, Krone W \& Muller-Wieland D. Identification of mutations of the arginine vasopressin-neurophysin II gene in two kindreds with familial central diabetes insipidus. Journal of Clinical Endocrinology and Metabolism 1998 83 693-696.

31 Calvo B, Bilbao JR, Urrutia I, Eizaguirre J, Gaztambide S \& Castano L. Identification of a novel nonsense mutation and a missense substitution in the vasopressin-neurophysin II gene in two Spanish kindreds with familial neurohypophyseal diabetes insipidus. Journal of Clinical Endocrinology and Metabolism 1998 83 995-997.

32 Grant FD, Ahmadi A, Hosley CM \& Majzoub JA. Two novel mutations of the vasopressin gene associated with familial diabetes insipidus and identification of an asymptomatic carrier infant. Journal of Clinical Endocrinology and Metabolism $1998 \mathbf{8 3}$ $3958-3964$

33 Calvo B, Bilbao J, Rodriguez A, Rodriguez-Arnao MD \& Castano L. Molecular analysis in familial neurohypophyseal diabetes insipidus: early diagnosis of an asymptomatic carrier. Journal of Clinical Endocrinology and Metabolism 199984 3351-3354.

34 Fujii H, Iida S \& Moriwaki K. Familial neurohypophyseal diabetes insipidus associated with a novel mutation in the vasopressinneurophysin II gene. International Journal of Molecular Medicine 20005 229-234.

35 Willcutts MD, Felner E \& White PC. Autosomal recessive familial neurohypophyseal diabetes insipidus with continued secretion of mutant weakly active vasopressin. Human Molecular Genetics 19998 1303-1307.

36 Burman S, Wellner D, Chait B, Chaudhary T \& Breslow E. Complete assignment of neurophysin disulfides indicates pairing in two separate domains. PNAS 198986 429-433.

37 Chen LQ, Rose JP, Breslow E, Yang D, Chang WR, Furey WFJ et al. Crystal structure of a bovine neurophysin II dipeptide complex at $2.8 \AA$ determined from the single-wavelength anomalous scattering signal of an incorporated iodine atom. PNAS $1991 \mathbf{8 8}$ $4240-4244$

38 Schmale H \& Richter D. Single base deletion in the vasopressin gene is the cause of diabetes insipidus in Brattleboro rats. Nature 1984308 705-709.

39 Olias G, Richter D \& Schmale H. Heterologous expression of human vasopressin-neurophysin precursors in a pituitary cell line: defective transport of a mutant protein from patients with familial diabetes insipidus. DNA and Cell Biology 199615 929935.

40 Ito M, Jameson JL \& Ito M. Molecular basis of autosomal dominant neurohypophyseal diabetes insipidus. Cellular toxicity caused by the accumulation of mutant vasopressin precursors within the endoplasmic reticulum. Journal of Clinical Investigation 199799 1897-1905.

41 Beuret N, Rutishauser J, Bider MD \& Spiess M. Mechanism of endoplasmic reticulum retention of mutant vasopressin precursor caused by a signal peptide truncation associated with diabetes insipidus. Journal of Biological Chemistry $1999 \mathbf{2 7 4}$ 18965-18972.

42 Ito M, Oiso Y, Murase T, Kondo K, Saito H, Chinzei T et al. Possible involvement of inefficient cleavage of preprovasopressin by signal peptidase as a cause for familial central diabetes insipidus. Journal of Clinical Investigation 199391 2565-2571.

43 Ito M, Yu RN, Jameson JL \& Ito M. Mutant vasopressin precursors that cause autosomal dominant neurohypophyseal diabetes insipidus retain dimerization and impair the secretion of the wild-type proteins. Journal of Biological Chemistry $1999 \mathbf{2 7 4}$ 9029-9037.

44 Deladoey J \& Mullis PE. Effect of the dominant negative human growth hormone $(\mathrm{HGH})$ gene mutation $\mathrm{Arg} 183 \mathrm{His}$ on the regulated secretory pathway. Growth Hormone and IGF Research 200010148 (Abstract 064).

45 Deladoëy J, Stocker P \& Mullis PE. Autosomal dominant growth hormone (GH) deficiency due to an Arg183His GH-1 gene mutation: clinical and molecular evidence of impaired regulated GH secretion. Journal of Clinical Endocrinology and Metabolism 2001 (In Press).

Received 31 January 2001

Accepted 5 June 2001 